\title{
BMJ Open Respiratory distress syndrome in moderately late and late preterm infants and risk of cerebral palsy: a population-based cohort study
}

\author{
Sandra Kruchov Thygesen, ${ }^{1}$ Morten Olsen, ${ }^{1}$ John R Østergaard, ${ }^{2}$ \\ Henrik Toft Sørensen ${ }^{1,3}$
}

To cite: Thygesen SK, Olsen M, Østergaard JR, et al. Respiratory distress syndrome in moderately late and late preterm infants and risk of cerebral palsy: a population-based cohort study. BMJ Open 2016;6: e011643. doi:10.1136/ bmjopen-2016-011643

- Prepublication history and additional material is available. To view please visit the journal (http://dx.doi.org/ 10.1136/bmjopen-2016011643).

Received 23 February 2016 Revised 9 September 2016 Accepted 14 September 2016

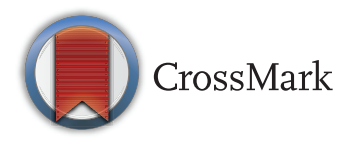

\footnotetext{
${ }^{1}$ Department of Clinical Epidemiology, Aarhus University Hospital, Aarhus N, Denmark

2Department of Paediatrics, Aarhus University Hospital, Aarhus N, Denmark ${ }^{3}$ Departments of Health Research and Policy (Epidemiology), Stanford University, Stanford, California, USA
}

Correspondence to Dr Sandra Kruchov Thygesen; st@clin.au.dk

\section{ABSTRACT \\ Objectives: Infant respiratory distress syndrome (IRDS) is a known risk factor for intracerebral haemorrhage/intraventricular haemorrhage (ICH/IVH) and periventricular leucomalacia. These lesions are known to increase the risk of cerebral palsy (CP). Thus, we wanted to examine the long-term risk of $\mathrm{CP}$ following IRDS in moderately late and late preterm infants.}

Design: Population-based cohort study.

Setting: All hospitals in Denmark.

Participants: We used nationwide medical registries to identify a cohort of all moderately and late preterm infants (defined as birth during 32-36 full gestational weeks) born in Denmark in 1997-2007 with and without hospital diagnosed IRDS.

Main outcomes measures: We followed study participants from birth until first diagnosis of $\mathrm{CP}$, emigration, death or end of follow-up in 2014. We computed the cumulative incidence of CP before age 8 years and used Cox's regression analysis to compute HRs of IRDS, comparing children with IRDS to those without IRDS. HRs were adjusted for multiple covariates.

Results: We identified 39420 moderately late and late preterm infants, of whom $2255(5.7 \%)$ had IRDS. The cumulative incidence of CP was $1.9 \%$ in infants with IRDS and $0.5 \%$ in the comparison cohort. The adjusted HR of CP was 2.0 (95\% Cl 1.4 to 2.9$)$. The adjusted HR of CP was 12 (95\% Cl 4.5 to 34 ) in children with IRDS accompanied by a diagnosis of ICH/IVH. After restriction to children without diagnoses of perinatal breathing disorders other than IRDS, congenital heart disease and viral or bacterial infections occurring within 4 days of birth, the overall adjusted $\mathrm{HR}$ was $2.1(95 \% \mathrm{Cl}$ 1.4 to 3.1 ).

Conclusions: The risk of CP was increased in moderately late and late preterm infants with IRDS compared with infants without IRDS born during the same gestational weeks.

\section{INTRODUCTION}

Increasing preterm birth rates over the last few decades have kept the overall incidence

\section{Strengths and limitations of this study}

- A strength of this study includes the nationwide cohort study design with virtually complete follow-up, minimising the risk of selection bias.

- To our knowledge, this is the first study to specifically determine the association between infant respiratory distress syndrome and cerebral palsy using multivariate analysis, and as such, the validity of the estimates presented is unknown.

- Even though this study is one of the largest examining a potential association between infant respiratory distress syndrome and cerebral palsy, it still does not clarify the specific causes leading to increased risk of cerebral palsy.

of infant respiratory distress syndrome (IRDS) high. ${ }^{1-3}$ IRDS decreases with increasing gestational age and has a prevalence of about $30 \%$ after 32 weeks of gestation. ${ }^{4-6}$ The condition is caused by lack of surfactant in the lungs, which leads to atelectasis, decreased gas exchange and hypoxia. Potential complications of IRDS include intracerebral haemorrhage/intraventricular haemorrhage (ICH/IVH) and periventricular leucomalacia (PVL). ${ }^{7} 8$ Studies have reported increased risk of neurodevelopmental impairments, such as neurocognitive and school performance outcomes as well as attention-deficit hyperactivity disorder (ADHD) in preterm children with subsequent hypoxic conditions, including IRDS. ${ }^{9} 10$

Cerebral palsy (CP) is the most common cause of severe disabilities in early childhood. ${ }^{11}$ The core symptom of CP is disorder of movement and/or posture, but is often accompanied by other neurodevelopmental disorders or sensory problems, such as disturbances of sensation, cognition, communication, perception, behaviour and/or seizure disorders. $^{12}$ The disorder has a multifactorial 
and poorly understood aetiology. The most important risk factor for CP is preterm birth, observed in about $28-35 \%$ of all children with CP. ${ }^{13}{ }^{14}$ Major lesions that contribute to CP include ICH/IVH and PVL. ${ }^{7} 1516$

Few data exist on the long-term prognosis following IRDS. A few case-control studies have reported indications of an association between IRDS and $\mathrm{CP}^{17-19}$ However, these studies are limited by small sample sizes and lack of absolute risk estimates. In the present study, we therefore examined the association between IRDS and $\mathrm{CP}$ in a nationwide follow-up study of children born moderately and late preterm.

\section{METHODS}

\section{Setting and data linkage}

We conducted this cohort study using population-based medical databases covering the entire country of Denmark. Linkage between databases was possible through the Civil Registration System (CRS), which has kept electronic records of birth date, date of emigration and date of death since $1968 .^{20}$ At birth or on immigration, all Danish residents are assigned a unique Civil Personal Registration (CPR) number that is used in all public Danish registries. The Danish National Health Service provides free tax-supported healthcare to the country's 5.6 million citizens.

\section{Study cohort}

Our cohort was identified using the Danish Medical Birth Registry, which contains information on all births in Denmark since 1973. We identified all infants born alive in Denmark from 1 January 1997 to 31 December 2007 ( 710 000 infants) $)^{21} 22$ and then restricted our cohort to moderately late and late preterm infants (defined as birth between 32 and 36 full weeks). Adequate representation of children with and without IRDS is available during these gestational weeks.

\section{Infant respiratory distress syndrome}

We identified all children diagnosed with IRDS (exposed children) in the Danish National Patient Registry (DNPR). The DNPR contains data on all nonpsychiatric hospital admissions in the country since 1977 and on outpatient clinic and emergency room visits since 1995. ${ }^{23}{ }^{24}$ Data include dates of admission and discharge, surgical procedure(s) performed, and one primary diagnosis and up to 19 secondary diagnoses coded by the discharging physician according to the International Classification of Diseases, Eighth Edition (ICD-8) until the end of 1993 and the Tenth Edition (ICD-10) thereafter.

\section{Cerebral palsy}

Children diagnosed with CP were identified from the Danish National Cerebral Palsy Registry (DNCPR). Prerequisites for inclusion in this registry are a prenatal or perinatal aetiology (events occurring within 28 days of birth).
All children included in the registry had their diagnosis externally validated by a child neurologist at the age of 4-5 years, based on review of clinical findings recorded in the medical files. While the registry includes data on prenatally and perinatally acquired cases of CP since 1950, it became nationwide only in 1995. DNCPR is assumed to cover $>85 \%$ of the children with CP in Denmark. ${ }^{25}$ Registry data include subtype and degree of $\mathrm{CP},{ }^{11}$ predefined ranges of developmental quotient (DQ: $<50,50-85,>85$ ), motor handicap measured by the Gross Motor Function Classification System (GMFCS, 0-4) (though only complete until birth year 2003), accompanying neurological diseases and orthopaedic surgeries. Results of ultrasound and CT scans of the brain and evaluation of timing of brain damage are available. ${ }^{25}$ The DQ were mostly based on a clinical evaluation by a neuropaediatrician, because the results of the psychological assessments were rarely available in the medical files. The GMFCS is a tool used to measure gross motor skills in children with CP. The classification system ranges from level 1 (walking with no support) up to level 5 (immobile/impaired in all areas of motor function) ${ }^{26}$ We obtained the following study outcomes from the registry: overall diagnosis of CP, selected subtypes of CP (unilateral and bilateral spastic CP), motor handicap degree (GMFCS levels 1-2, 3 and 4-5) and DQ $(<50$, $50-85$ and $>85)$.

\section{Covariates}

We obtained information from the Danish Medical Birth Registry for the entire cohort on gestational age at birth, 5 min Apgar score, chorioamnionitis, intrauterine growth restriction, abruptio placenta, multiplicity, maternal age and self-reported maternal smoking during pregnancy. ${ }^{22}$ Of note, information on administration of antenatal corticosteroids was not available. In the early years, weeks of gestation was based on the first day of the last menstrual period. Later, prenatal ultrasound measurements were also included as a valid measure for the gestational age. However, in the Danish Medical Birth Registry, it is not possible to distinguish between the methods of measurement used to determine gestational age. ${ }^{21}$ We used data from the DNPR to ascertain the distribution of complications in children with and without IRDS, including bronchopulmonary dysplasia, $\mathrm{ICH} / \mathrm{IVH}$, necrotising enterocolitis and patent ductus arteriosus (see online supplementary appendix A). Congenital malformations are associated with increased risk of CP and also may be associated with IRDS. We therefore ascertained from the DNPR all diagnoses of congenital malformations detected during the first year of life.

A subgroup of children may have had other conditions within 4 days of birth whose symptoms potentially overlapped with IRDS and may potentially lead to misdiagnosis of IRDS. These diseases include perinatal breathing disorders other than IRDS, congenital heart diseases, and viral and bacterial infections. We 
identified these conditions from the DNPR (see online supplementary appendix A).

\section{Statistical analysis}

We followed all children in the study cohort from date of birth until the date of the first diagnosis of CP, emigration, death or 31 December 2014, whichever came first. We computed the cumulative incidence of CP before 8 years of age with death as a competing risk. ${ }^{27}$ In a subanalysis, the commonest subtypes of CP were analysed as separate outcomes (unilateral and bilateral spastic CP), as well as motor handicap degree (GMFCS $1-2,3$ and 4-5) (only valid until birth year 2003) and developmental quotient $(<50,50-85$, and $>85)$.

We used Cox proportional hazard regression to estimate unadjusted and adjusted HRs for CP among children with IRDS compared with children without IRDS. The analyses were adjusted for gestational age (32, 33, 34, 35 and 36 weeks of gestation), birth year (1997-1999, 2000-2002, 2003-2005 and 2006-2007), gender, multiplicity (singleton/twins), major malformations and maternal age ( $<35$ and $\geq 35$ years of age). The assumptions of proportional hazards were all verified graphically. We considered a low 5 min Apgar score as a causal intermediate step between IRDS and CP and, thus, did not include this covariate as a confounder in the adjusted analyses. However, we did include 5-min Apgar score in the regression model in a subanalysis. Chorioamnionitis, intrauterine growth restriction and abruptio placenta are important independent risk factors of CP. Moreover, these conditions are associated with IRDS, not independently, but through low gestational age. Though, they did not qualify as confounders in the association between IRDS and CP, we did include the three covariates as confounders in a subanalysis.

We stratified the analyses on gestational age (birth at 32, 33, 34 and 35-36 full weeks), birth year (1997-2002, 2003-2007), gender, multiplicity, 5-min Apgar score $(0-6,7-8,9-10$, missing), and maternal age $(<35$ and $\geq 35$ years of age) and calculated $95 \%$ CIs. ICH/IVH is a known complication of IRDS and an important risk factor for CP. We, therefore, repeated the analyses for children with IRDS and a diagnosis of ICH/IVH within 30 days of birth compared with children with IRDS and no diagnosis of ICH/IVH. Of note, cranial ultrasound is not performed as a routine in moderately late and late preterm infants, so the proportion of infants with a diagnosis of ICH/IVH is based on detection in only infants selected for neuroimaging based on clinical presentation and risk factors.

Perinatal diseases may be misinterpreted as IRDS because of overlapping clinical symptoms or coexist with IRDS. Such perinatal disorders include perinatal breathing disorders other than IRDS, congenital heart diseases and viral and bacterial infections. Thus, in a sensitivity analysis,
Table 1 Characteristics of 39420 infants born during 32-36 weeks of gestation with and without infant respiratory distress syndrome (IRDS), between 1 January 1997 and 31 December 2007 in Denmark

\begin{tabular}{|c|c|c|}
\hline & IRDS, n (\%) & $\begin{array}{l}\text { No IRDS, } \\
\text { n (\%) }\end{array}$ \\
\hline All & $2255(100.0)$ & $37165(100.0)$ \\
\hline \multicolumn{3}{|c|}{ Gestational age (week of gestation) } \\
\hline 32 & $602(26.7)$ & $2058(5.5)$ \\
\hline 33 & $545(24.2)$ & $3313(8.9)$ \\
\hline 34 & $526(23.3)$ & $5652(15.2)$ \\
\hline 35 & $346(15.3)$ & $9156(24.6)$ \\
\hline 36 & $236(10.5)$ & $16986(45.7)$ \\
\hline \multicolumn{3}{|l|}{ Birth year } \\
\hline 1997-1999 & $534(23.7)$ & $9379(25.2)$ \\
\hline 2000-2002 & $602(26.7)$ & $10443(28.1)$ \\
\hline 2003-2005 & 696 (30.9) & $10433(28.1)$ \\
\hline 2006-2007 & $423(18.8)$ & $6910(18.6)$ \\
\hline \multicolumn{3}{|l|}{ Gender } \\
\hline Female & $897(39.8)$ & $17184(46.2)$ \\
\hline Male & $1358(60.2)$ & $19.981(53.8)$ \\
\hline \multicolumn{3}{|l|}{ Apgar score at $5 \mathrm{~min}$} \\
\hline Low $(0-6)$ & $111(4.9)$ & $646(1.7)$ \\
\hline Intermediate (7-8) & $271(12.0)$ & $1824(4.9)$ \\
\hline Normal $(9-10)$ & $1816(80.5)$ & 33974 (91.4) \\
\hline Missing & $57(2.5)$ & $721(1.9)$ \\
\hline \multicolumn{3}{|l|}{ Multiplicity } \\
\hline Singleton & $1644(72.9)$ & $27438(73.8)$ \\
\hline Twin & $611(27.1)$ & $9727(26.2)$ \\
\hline Epilepsy & $53(2.4)$ & $590(1.6)$ \\
\hline $\begin{array}{l}\text { Major malformation } \\
\text { ( }<1 \text { year) }\end{array}$ & $217(9.6)$ & $2525(6.8)$ \\
\hline \multicolumn{3}{|l|}{ Mother's age at delivery } \\
\hline$<18$ years & $5(0.2)$ & $130(0.4)$ \\
\hline 18-34 years & $1807(80.1)$ & $30131(81.1)$ \\
\hline$\geq 35$ years & $443(19.7)$ & $6903(18.6)$ \\
\hline Missing & $0(0.0)$ & $1(0.0)$ \\
\hline \multicolumn{3}{|c|}{ Maternal smoking status } \\
\hline $\begin{array}{l}\text { Non smoker/former } \\
\text { smoker }\end{array}$ & $1689(74.9)$ & 26487 (71.3) \\
\hline Smoker & 403 (17.9) & 8433 (22.7) \\
\hline Missing & $163(7.2)$ & $2245(6.0)$ \\
\hline \multicolumn{3}{|c|}{ Bronchopulmonary dysplasia (BPD) (<1 year) } \\
\hline Yes & $22(1.0)$ & $16(0.1)$ \\
\hline \multicolumn{3}{|c|}{$\begin{array}{l}\text { Intracerebral haemorrhage /intraventricular haemorrhage } \\
(\mathrm{ICH} / \mathrm{IVH})(<30 \text { days })^{*}\end{array}$} \\
\hline Yes & $46(2.0)$ & $121(0.3)$ \\
\hline \multicolumn{3}{|c|}{ Necrotising enterocolitis (NEC) (<30 days) } \\
\hline Yes & $20(0.9)$ & $59(0.2)$ \\
\hline \multicolumn{3}{|c|}{ Patent ductus arteriosus (PDA) (<30 days) } \\
\hline Yes & $77(3.4)$ & $239(0.6)$ \\
\hline \multicolumn{3}{|l|}{ Other diseases $\dagger$} \\
\hline Yes & $682(30.2)$ & $6641(17.9)$ \\
\hline \multicolumn{3}{|c|}{$\begin{array}{l}\text { *Information on total number of infants undergoing cranial } \\
\text { ultrasound examination is unavailable. } \\
\text { tOther diseases whose symptoms may overlap with those of } \\
\text { IRDS, occurring within } 4 \text { days of birth (perinatal breathing } \\
\text { disorders other than IRDS, congenital heart diseases, and viral } \\
\text { and bacterial infections). }\end{array}$} \\
\hline
\end{tabular}


we restricted the IRDS cohort to newborns with no other perinatal disorders occurring within 4 days of birth.

All analyses were performed using the Stata 13.1 package (StataCorp LP, College Station, TX, USA). According to Danish legislation, registry-based studies do not need permission from an ethical board. The study was approved by the Danish Protection Agency (record number: 2014-41-3183) and did not require informed consent.

\section{Patient involvement}

No patients were involved in setting the research question or the outcome measures, nor were they involved in developing plans for design or implementation of the study. No patients were asked to advise on interpretation or writing up of results. There are no plans to disseminate the results of the research to study participants or the relevant patient community.

\section{RESULTS}

From the Danish Medical Birth Registry, we identified 39420 children born moderately and late preterm between 1997 and 2007. Of these, 2255 (5.7\%) were diagnosed with IRDS. Having another perinatal disorder occurring within 4 days of birth, including perinatal breathing disorders other than IRDS, congenital heart diseases, and viral and bacterial infection were more prevalent in the children with IRDS (30\%) compared with children without IRDS (18\%) (table 1).

The cumulative incidence of CP before 8 years of age was 1.9 (95\% CI 1.4 to 2.5$)$ in children with IRDS and 0.5 (95\% CI 0.4 to 0.6 ) in children without IRDS (figure 1). The overall crude HR for CP in children with IRDS compared with children without IRDS was 4.0 (95\% CI 2.9 to 5.6). After adjusting for gestational age, birth year, gender, multiplicity, major malformations and maternal age, the HR was 2.0 (95\% CI 1.4 to 2.9) (table 2).

When we stratified the analysis by gestational age, we found an increased risk of $\mathrm{CP}$ across all strata in children with IRDS compared with children without IRDS. As well, we found no substantial variation in the increased risk of CP in children with IRDS across categories of gender, year of birth, multiplicity, 5-min Apgar score and maternal age, although these estimates were less precise. The adjusted HR of CP was 12 (95\% CI 4.5 to 34$)$ in children with IRDS complicated by a discharge diagnosis of ICH/IVH.

Including 5-min Apgar score as a potential confounder in the regression model did not change our estimates substantially. The same was evident, when we included chorioamnionitis, intrauterine growth restriction and abruptio placenta as potential confounders in the regression analysis (overall HR of 2.0 (95\% CI 1.4 to 2.9)). When restricting to children diagnosed with IRDS and no other relevant coexisting diagnoses occurring within 4 days of birth (ie, perinatal breathing disorders other than IRDS, congenital heart diseases, and viral and bacterial infections), the overall adjusted HR was 2.1 (95\% CI 1.4 to 3.1$)$.

The most common subtype of CP was unilateral and bilateral spastic CP (data not shown). For children diagnosed with IRDS, we found an HR of 1.5 (95\% CI 0.8 to 2.9) for unilateral spastic CP and 2.2 (95\% CI 1.4 to 3.4) for bilateral spastic CP. The HR was 1.9 (95\% CI 1.1 to 3.4) for CP with a normal DQ (above 85), 1.7 (95\% CI 0.9 to 3.1) for a DQ between 50 and 85, and $2.9(95 \%$ CI 1.4 to 6.1) for a DQ below 50 (table 3).

In children with IRDS born during 1997-2003, the HR was 2.2 (95\% CI 1.3 to 3.9 ) for a mild degree of motor handicap (GMFCS 1-2) and 2.5 (95\% CI 1.3 to 4.7) for a severe degree of motor handicap (GMFCS 45) (table 3).
Figure 1 Cumulative incidence of cerebral palsy in 24728 children with and without infant respiratory distress syndrome (IRDS) in Denmark during 1997-2003.

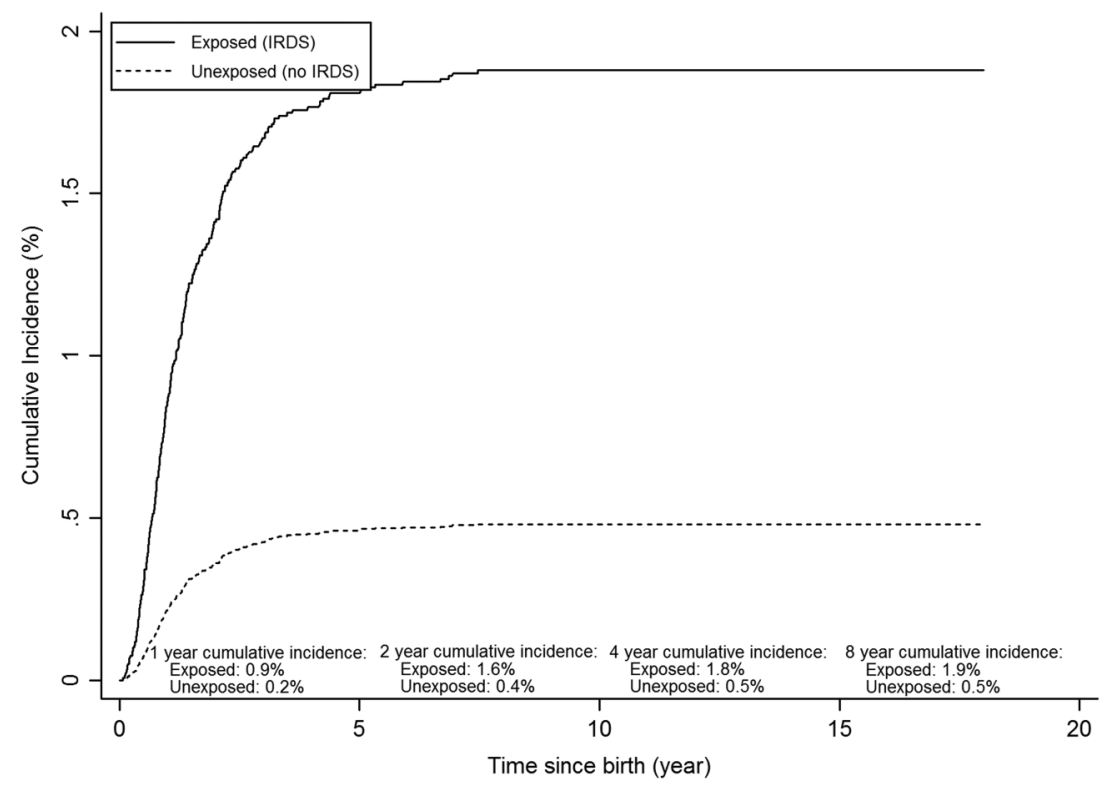


Table 2 HRs of cerebral palsy (CP) by age 8 among children with and without infant respiratory distress syndrome (IRDS) born during $32-36$ weeks of gestation between 1992 and 2007 in Denmark. (N=39 410)

\begin{tabular}{|c|c|c|c|c|c|c|}
\hline & \multicolumn{2}{|c|}{ Number of children with CP } & \multicolumn{2}{|c|}{ 8-year cumulative incidence, $\%(95 \% \mathrm{Cl})$} & \multirow[b]{2}{*}{ Crude HR (95\% CI) } & \multirow[b]{2}{*}{ Adjusted HR ${ }^{*}(95 \% \mathrm{Cl})$} \\
\hline & Children with IRDS & $\begin{array}{l}\text { Children without } \\
\text { IRDS }\end{array}$ & Children with IRDS & Children without IRDS & & \\
\hline Overall & 42 & 178 & $1.9(1.4$ to 2.5$)$ & $0.5(0.4$ to 0.6$)$ & $4.0(2.9$ to 5.6$)$ & $2.0(1.4$ to 2.9$)$ \\
\hline \multicolumn{7}{|l|}{ Gestational age } \\
\hline 32 weeks of gestation & 21 & 31 & 3.5 (2.2 to 5.2$)$ & 1.5 (1.1 to 2.1$)$ & $2.3(1.3$ to 4.0$)$ & 2.4 (1.4 to 4.2$)$ \\
\hline 33 weeks of gestation & 11 & 44 & $2.0(1.1$ to 3.5$)$ & $1.3(1.0$ to 1.7$)$ & $1.6(0.8$ to 3.1$)$ & $1.6(0.8$ to 3.1$)$ \\
\hline 34 weeks of gestation & 7 & 30 & $1.4(0.6$ to 2.7$)$ & $0.5(0.4$ to 0.8$)$ & 2.5 (1.1 to 5.8$)$ & 2.5 (1.1 to 5.8$)$ \\
\hline (35-36) weeks of gestation & 3 & 73 & $0.5(0.1$ to 1.4$)$ & $0.3(0.2$ to 0.4$)$ & $1.9(0.6$ to 6.1$)$ & $1.7(0.5$ to 5.5$)$ \\
\hline \multicolumn{7}{|l|}{ Calendar year } \\
\hline (1997-2002) & 28 & 105 & 2.5 (1.7 to 3.5$)$ & 0.5 (0.4 to 0.6$)$ & 4.8 (3.2 to 7.3 ) & 2.4 (1.5 to 3.7 ) \\
\hline (2003-2007) & 14 & 73 & $1.3(0.7$ to 2.1$)$ & $0.4(0.3$ to 0.5$)$ & 3.1 (1.7 to 5.4$)$ & $1.4(0.8$ to 2.6$)$ \\
\hline \multicolumn{7}{|l|}{ Gender } \\
\hline Female & 14 & 76 & 1.6 (0.9 to 2.6$)$ & $0.4(0.4$ to 0.6$)$ & 3.6 (2.1 to 6.4 ) & 1.7 (0.9 to 3.1$)$ \\
\hline Male & 28 & 102 & $2.1(1.4$ to 3.0$)$ & $0.5(0.4$ to 0.6$)$ & 4.2 (2.7 to 6.3$)$ & $2.2(1.4$ to 3.4$)$ \\
\hline \multicolumn{7}{|l|}{ Apgar score at $5 \mathrm{~min}$} \\
\hline Low (0-6) & 4 & 10 & 3.7 (1.2 to 8.5$)$ & $1.6(0.8$ to 2.8$)$ & 2.1 (0.7 to 6.8$)$ & 2.2 (0.7 to 7.7$)$ \\
\hline Intermediate (7-8) & 7 & 31 & 2.6 (1.2 to 5.0$)$ & 1.7 (1.2 to 2.4$)$ & $1.6(0.7$ to 3.5$)$ & $1.2(0.5$ to 2.8$)$ \\
\hline Normal (9-10) & 28 & 131 & 1.6 (1.1 to 2.2$)$ & $0.4(0.3$ to 0.5$)$ & 4.1 (2.7 to 6.2 ) & 1.9 (1.2 to 2.9$)$ \\
\hline Missing & 3 & 6 & $5.3(1.4$ to 13$)$ & $0.8(0.4$ to 1.8$)$ & $6.6(1.6$ to 26$)$ & $6.0(1.0$ to 35$)$ \\
\hline \multicolumn{7}{|l|}{ Multiplicity } \\
\hline Singleton & 29 & 129 & 1.8 (1.2 to 2.5$)$ & $0.5(0.4$ to 0.6$)$ & 3.9 (2.6 to 5.8$)$ & 2.0 (1.3 to 3.1$)$ \\
\hline Twin & 13 & 49 & 2.1 (1.2 to 3.5$)$ & 0.5 (0.4 to 0.7$)$ & 4.3 (2.3 to 7.9 ) & 1.9 (1.0 to 3.6$)$ \\
\hline \multicolumn{7}{|l|}{ Maternal age } \\
\hline Younger than 35 years of age & 31 & 138 & $1.7(1.2$ to 2.4$)$ & $0.5(0.4$ to 0.5$)$ & $3.9(2.6$ to 5.7$)$ & $1.9(1.3$ to 2.9$)$ \\
\hline 35 years of age or older & 11 & 40 & 2.5 (1.3 to 4.3$)$ & $0.6(0.4$ to 0.8$)$ & $4.4(2.3$ to 8.6$)$ & 2.3 (1.1 to 4.8$)$ \\
\hline
\end{tabular}


Table 3 HRs of cerebral palsy (CP) among children with and without infant respiratory distress syndrome (IRDS) born during 32-36 weeks of gestation between 1992 and 2007 in Denmark

\begin{tabular}{|c|c|c|c|c|}
\hline & \multicolumn{4}{|c|}{ Number of children with CP } \\
\hline & Children with IRDS & Children without IRDS & Crude HR $(95 \% \mathrm{Cl})$ & Adjusted HR $(95 \% \mathrm{Cl})$ \\
\hline \multicolumn{5}{|l|}{ Selected subtypes $\dagger$} \\
\hline Unilateral spastic CP & 12 & 74 & $2.7(1.5-5.0)$ & $1.5(0.8-2.9)$ \\
\hline Bilateral spastic CP & 26 & 87 & $5.1(3.3-7.9)$ & $2.2(1.4-3.4)$ \\
\hline \multicolumn{5}{|c|}{ Motor handicap (1997-2003)‡ } \\
\hline GMFCS $1-2 \S$ & 16 & 71 & $4.0(2.3-6.8)$ & $2.2(1.3-3.9)$ \\
\hline GMFCS 3 & 1 & 4 & $4.4(0.5-39)$ & $2.2(0.2-21)$ \\
\hline GMFCS 4-5 & 4 & 70 & $6.1(3.3-11)$ & $2.5(1.3-4.7)$ \\
\hline \multicolumn{5}{|c|}{ Developmental quotient (DQ) } \\
\hline$D Q<50$ & 11 & 33 & $5.6(2.8-11)$ & $2.9(1.4-6.1)$ \\
\hline DQ 50-85 & 14 & 60 & $3.9(2.2-7.0)$ & $1.7(0.9-3.1)$ \\
\hline $\mathrm{DQ}>85$ & 17 & 80 & $3.6(2.1-6.1)$ & $1.9(1.1-3.4)$ \\
\hline
\end{tabular}

\section{DISCUSSION}

We found an increased risk of CP associated with IRDS in children born moderately late and late preterm.

Other studies have shown increased risk of neurodevelopmental impairments, defined by psychomotor development and school readiness, in preterm children with IRDS. ${ }^{9} 102829$ Studies have looked at possible causes or predictors of $\mathrm{CP}$ in different settings and found modest associations. In an Australian case-control study, Blair et al reported an OR of CP of 2.3 (95\% CI 1.3 to 4.3); and in another case-control study from Western Australia, Dite et al found an OR of 9.4 (95\% CI 1.8 to 48 ) in children diagnosed with IRDS. However, even though they reported increased risk estimates of $\mathrm{CP}$ in children with IRDS, the estimates were based on univariate analyses in relatively small study populations. Thus, potential confounders were not taken into consideration, and no absolute measures were available. ${ }^{17-19}$ In a cohort study, Hirvonen et al found a negative association between IRDS and CP in late preterm infants. However, apparently the multivariate model included intermediate steps between IRDS and CP in terms of mechanical ventilator treatment and intracranial haemorrhage. Furthermore, the analysis was not based on time-to-event methods, but based on logistic regression. ${ }^{30}$ This may have explained the differences between their results and ours.

Through data linkage performed by the Danish CRS, this population-based study had virtually complete follow-up for death, emigration and hospital admissions, minimising the risk of selection bias. As lack of surfactant cannot be measured directly, the diagnosis of IRDS is based on the clinical appearance of the infant; thus, it is not possible to make a clear and consistent diagnostic test. We previously reported a positive predictive value of $89 \%$ (95\% CI $75 \%$ to $96 \%$ ) for children with IRDS born between 32 and 36 weeks of gestation in the DNPR. ${ }^{31}$ In this study, IRDS was based exclusively on clinical symptoms, as X-rays were only used infrequently early in the study period. Additionally, in a sensitivity analysis, we redefined our exposure of children with IRDS to only those having IRDS with no other perinatal disorders occurring within 4 days of birth. Our estimates were virtually unchanged in this analysis. As the CP Registry is a clinical database based on specific inclusion criteria including thorough medical record review of all children with CP in Denmark, we expect the positive predictive value of the $\mathrm{CP}$ diagnosis to be close to $100 \%$. A previous validation study of the DNCPR through the DNPR reported its completeness to be $85 \% .{ }^{25}$ As any misclassification is not likely associated with IRDS, such non-differential bias would eventually lead to an underestimation of the association between IRDS and CP.

One of the strongest risk factors for development of $\mathrm{CP}$ is known to be low gestational age ${ }^{32}{ }^{33}$ which is also the strongest risk factor for IRDS. For this reason, we stratified our analyses on gestational age to ensure that any increased risk of CP in children with IRDS was not masked by this association. After taking this precaution, we still found an increased risk of CP among children born during gestational weeks 32-34. Only a few children diagnosed with CP were born during 35 and 36 weeks of gestation, which made calculations of the HR imprecise.

To study rare disease like CP large study populations are required, especially when the study sample is restricted to children born at 32-36 gestational weeks. For this reason, we were only able to present overall estimates in our analyses of selected subtypes of CP, degree of motor handicap and DQ. These estimates were all increased throughout all levels of CP severity. Of note, the prespecified DQ score category, including scores of 50-85, encompassed children with normal intelligence as well as delayed children, indicating a diverse group. Thus, not too much emphasis should be given to this group. 
Even though this study is among the largest studies examining a potential association between IRDS and CP by using data from nationwide databases on preterm infants, it still does not clarify the specific causes of the increased risk of CP. We found a 12-fold increase of CP in children with IRDS and a diagnosis of ICH/IVH compared with our control population. This may suggest an important role of ICH/IVH in the pathogenesis, though this is only a speculation. ${ }^{15} 34{ }^{35}$ In moderately late and late preterm infants, neuroimaging is not routinely performed, indicating that some of these children may have an undiagnosed ICH/IVH. Based on this, the proportion of children with ICH/IVH may have been underestimated in the exposed group as well as in the comparison cohort, making the HR imprecise.

Antenatal corticosteroids decrease the risk of IRDS, as well as ICH/IVH. However, recent studies have reported adverse neurodevelopment outcomes in children receiving antenatal steroids. ${ }^{36}$ We did not have information of treatment with antenatal corticosteroids, which is a limitation of our study.

IRDS potentially could be a surrogate for another unknown medical condition. However, recognition of an early predictor of increased future CP risk could still be helpful when planning follow-up and/or intervention strategies in children born preterm.

\section{CONCLUSION}

We found that the risk of CP was twice as high in moderately late and late preterm infants with IRDS compared with infants without IRDS born during the same gestational weeks.

Contributors SKT conceptualised and designed the study, acquired the data, carried out the analyses, drafted the initial manuscript, reviewed and revised the manuscript and approved the final manuscript as submitted. MO, JRO and HTS conceptualised and designed the study, supervised the data interpretation, critically reviewed and revised the manuscript for important intellectual content and approved the final manuscript as submitted. MO helped to acquire the data and extract the raw data, critically supervised/ reviewed the data analyses and reviewed the data interpretation, revised the manuscript and approved the final manuscript as submitted.

Funding This study was supported by grants from the Clinical Epidemiological Research Foundation ('Klinisk Epidemiologisk Forskningsfond'), Denmark (HTS) and the Program for Clinical Research Infrastructure (PROCRIN) established by the Lundbeck and the Novo Nordisk Foundations (HTS). The funding agencies had no role in the design of the study; the collection, analysis and interpretation of the data; the writing of the article; or the decision to submit the article for publication.

Competing interests None declared.

Provenance and peer review Not commissioned; externally peer reviewed.

Author statement All authors, external and internal, had full access to all of the data (including statistical reports and tables) in the study and can take responsibility for the integrity of the data and the accuracy of the data analysis.

Transparency declaration SKT affirms that the study hypothesis arose before inspection of the data and that the manuscript is an honest, accurate and transparent account of the study being reported; that no important aspects of the study have been omitted; and that any discrepancies from the study as planned have been explained.

Data sharing statement No additional data are available.

Open Access This is an Open Access article distributed in accordance with the Creative Commons Attribution Non Commercial (CC BY-NC 4.0) license, which permits others to distribute, remix, adapt, build upon this work noncommercially, and license their derivative works on different terms, provided the original work is properly cited and the use is non-commercial. See: http:// creativecommons.org/licenses/by-nc/4.0/

\section{REFERENCES}

1. Blencowe $\mathrm{H}$, Cousens $\mathrm{S}$, Oestergaard $\mathrm{MZ}$, et al. National, regional, and worldwide estimates of preterm birth rates in the year 2010 with time trends since 1990 for selected countries: a systematic analysis and implications. Lancet 2012;379:2162-72.

2. Goldenberg RL, Culhane JF, lams JD, et al. Epidemiology and causes of preterm birth. Lancet 2008;371:75-84.

3. Saigal S, Doyle LW. An overview of mortality and sequelae of preterm birth from infancy to adulthood. Lancet 2008;371:261-9.

4. Robertson PA, Sniderman SH, Laros RK, et al. Neonatal morbidity according to gestational age and birth weight from five tertiary care centers in the United States, 1983 through 1986. Am J Obstet Gynecol 1992;166:1629-41; discussion 1641-5.

5. Koivisto M, Marttila R, Kurkinen-Raty M, et al. Changing incidence and outcome of infants with respiratory distress syndrome in the 1990s: a population-based survey. Acta Paediatr 2004;93:177-84.

6. Rubaltelli FF, Bonafe L, Tangucci M, et al. Epidemiology of neonatal acute respiratory disorders. A multicenter study on incidence and fatality rates of neonatal acute respiratory disorders according to gestational age, maternal age, pregnancy complications and type of delivery. Italian Group of Neonatal Pneumology. Biol Neonate 1998;74:7-15.

7. Kinney HC. The near-term (Late Preterm) human brain and risk for periventricular leukomalacia: a review. Semin Perinatol 2006;30:81-8

8. Sun $\mathrm{H}, \mathrm{XuF}$, Xiong $\mathrm{H}$, et al. Characteristics of respiratory distress syndrome in infants of different gestational ages. Lung 2013;191:425-33.

9. McGrath MM, Sullivan MC, Lester BM, et al. Longitudinal neurologic follow-up in neonatal intensive care unit survivors with various neonatal morbidities. Pediatrics 2000;106:1397.

10. Getahun D, Rhoads GG, Demissie K, et al. In utero exposure to ischemic-hypoxic conditions and attention-deficit/hyperactivity disorder. Pediatrics 2013;131:e53-61.

11. Surveillance of Cerebral Palsy in Europe. Surveillance of cerebral palsy in Europe: a collaboration of cerebral palsy surveys and registers. Surveillance of Cerebral Palsy in Europe (SCPE). Dev Med Child Neurol 2000;42:816-24.

12. Bax M, Goldstein M, Rosenbaum P, et al. Proposed definition and classification of cerebral palsy, April 2005. Dev Med Child Neurol 2005;47:571-6.

13. MacLennan AH, Thompson SC, Gecz J. Cerebral palsy: causes, pathways, and the role of genetic variants. Am J Obstet Gynecol 2015;213:779-88.

14. Jacobsson $B$, Hagberg G. Antenatal risk factors for cerebral palsy. Best Pract Res Clin Obstet Gynaecol 2004;18:425-36.

15. Futagi $Y$, Toribe $Y$, Ogawa K, et al. Neurodevelopmental outcome in children with intraventricular hemorrhage. Pediatr Neurol 2006;34:219-24.

16. Blair E, Stanley F. Aetiological pathways to spastic cerebral palsy. Paediatr Perinat Epidemiol 1993;7:302-17.

17. Stelmach T, Pisarev H, Talvik T. Ante- and perinatal factors for cerebral palsy: case-control study in Estonia. J Child Neurol 2005;20:654-60.

18. Dite GS, Bell R, Reddihough DS, et al. Antenatal and perinatal antecedents of moderate and severe spastic cerebral palsy. Aust $N$ Z J Obstet Gynaecol 1998;38:377-83.

19. Blair E, Stanley F. When can cerebral palsy be prevented? The generation of causal hypotheses by multivariate analysis of a case-control study. Paediatr Perinat Epidemiol 1993;7:272-301.

20. Schmidt M, Pedersen L, Sorensen HT. The Danish Civil Registration System as a tool in epidemiology. Eur J Epidemiol 2014;29:541-9.

21. Kristensen J, Langhoff-Roos J, Skovgaard LT, et al. Validation of the Danish Birth Registration. J Clin Epidemiol 1996;49:893-7.

22. Knudsen LB, Olsen J. The Danish Medical Birth Registry. Dan Med Bull 1998;45:320-3.

23. Lynge E, Sandegaard JL, Rebolj M. The Danish National Patient Register. Scand J Public Health 2011;39:30-3. 
24. Andersen TF, Madsen M, Jorgensen J, et al. The Danish National Hospital Register. A valuable source of data for modern health sciences. Dan Med Bull 1999;46:263-8.

25. Topp M, Langhoff-Roos J, Uldall P. Validation of a cerebral palsy register. J Clin Epidemiol 1997;50:1017-23.

26. Palisano R, Rosenbaum P, Walter S, et al. Development and reliability of a system to classify gross motor function in children with cerebral palsy. Dev Med Child Neurol 1997;39:214-23.

27. Gooley TA, Leisenring W, Crowley J, et al. Estimation of failure probabilities in the presence of competing risks: new representations of old estimators. Stat Med 1999;18:695-706.

28. Piekkala P, Kero P, Sillanpaa M, et al. Growth and development of infants surviving respiratory distress syndrome: a 2-year follow-up. Pediatrics 1987;79:529-37.

29. Patrianakos-Hoobler AI, Msall ME, Marks JD, et al. Risk factors affecting school readiness in premature infants with respiratory distress syndrome. Pediatrics 2009;124:258-67.
30. Hirvonen $\mathrm{M}$, Ojala $\mathrm{R}$, Korhonen $\mathrm{P}$, et al. Cerebral palsy among children born moderately and late preterm. Pediatrics 2014;134 e1584-93.

31. Thygesen SK, Olsen M, Christian FC. Positive predictive value of the infant respiratory distress syndrome diagnosis in the Danish National Patient Registry. Clin Epidemiol 2013;5:295-8.

32. Sukhov A, Wu Y, Xing G, et al. Risk factors associated with cerebral palsy in preterm infants. J Matern Fetal Neonatal Med 2012;25:53-7.

33. Topp M, Langhoff-Roos J, Uldall P. Preterm birth and cerebral palsy. Predictive value of pregnancy complications, mode of delivery, and Apgar scores. Acta Obstet Gynecol Scand 1997;76:843-8.

34. Harcke HT Jr, Naeye RL, Storch A, et al. Perinatal cerebral intraventricular hemorrhage. J Pediatr 1972;80:37-42.

35. Berg B. Neurology of the Newborn, 4th Edition, by J.J. Volpe. Muscle Nerve 2001;24:1099-.

36. Gyamfi-Bannerman C, Thom EA, Blackwell SC, et al. Antenatal Betamethasone for Women at Risk for Late Preterm Delivery. N Engl J Med 2016;374:1311-20. 